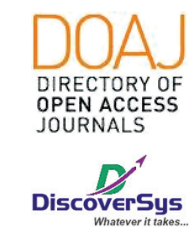

Published by DiscoverSys

\section{Prevalensi sarkopenia dan frailty di desa Pedawe, Mangupura, Serai dan Songan}

\author{
I Gusti Agung Wilaja Putra, ${ }^{1 *}$ I Gusti Putu Suka Aryana,${ }^{2}$ I Nyoman Astika, ${ }^{2}$ \\ RA Tuty Kuswardhani, ${ }^{2}$ Ida Bagus Putrawan, ${ }^{2}$ Ketut Rai Purnami ${ }^{2}$
}

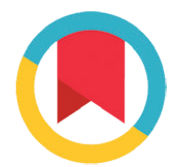

CrossMark

\section{ABSTRACT}

Background: Frailty is characterized by a decrease in multi-organ physiological functions. Sarcopenia and frailty have a significant impact on individuals and society so it is necessary to know the prevalence in the community. This study aimed to determine the prevalence of sarcopenia and frailty in rural areas.

Method: The was a cross-sectional study in the elderly population in the villages of Pedawa, Mangupura, Serai and Songan. Measurement of muscle mass using bioelectrical impedance analysis (BIA) and categorized based on the recommendation of the Asian Working Group for Sarcopenia (AWGS). Frailty is established through a screening questionnaire based on the Cardiovascular Health Study. The study was chosen by simple random sampling and population register data.

Results: The study involved 235 elderly people with 117 people in Pedawe village, 71 people in Mangupura village, 34 people in
Serai village and 13 people in Songan village with a composition of $35.5 \%$ men and $64.5 \%$ women. In this study sarcopenia in women was $51 \%$ and men $49 \%$, while frailty was experienced in $58.9 \%$ women and $41.02 \%$ men. The mean age is 67.7 years. The prevalence of total sarcopenia is $59 \%$ with the lowest percentage ranging from the villages of Mangupura (30\%), Songan (53.8\%), Pedawe (70.9\%), and Serai (79.4\%). The overall frailty prevalence in the four villages is $17 \%$ with the percentage starting from the lowest being Mangupura (1.4\%), Serai (5.9\%), Songan (22.2\%) and Pedawe (29.1\%).

Conclusions: The prevalence of sarcopenia and frailty is most common among elderly women. The highest prevalence of sarcopenia was found in Serai village and frailty prevalence was highest in Pedawe village.

Keywords: Elderly, sarcopenia, muscle mass, frailty

Cite This Article: Putra, I.G.A.W., Aryana, I.G.P.S., Astika, I.N., Kuswardhani, R.A.T., Putrawan, I.B., Purnami, K.R. 2020. Prevalensi sarkopenia dan frailty di desa Pedawe, Mangupura, Serai dan Songan. Intisari Sains Medis 11(2): 546-550. D0I: 10.15562/ism.v11i2.667

\title{
ABSTRAK
}

Latar Belakang: Frailty ditandai dengan adanya penurunan fungsi fisiologis multi organ. Sarkopenia dan frailty memberikan dampak yang bermakna bagi individu dan bagi masyarakat sehingga perlu untuk mengetahui prevalensinya di masyarakat. Penelitian ini bertujuan untuk mengetahui prevalensi sarkopenia dan frailty di daerah pedesaan. Metode: Penelitian menggunakan studi potong lintang pada populasi lansia di desa Pedawa, Mangupura, Serai dan Songan. Pengukuran massa otot menggunakan bioelectrical impedance analysis (BIA) dan dikategorikan berdasarkan rekomendasi Asian Working Group for Sarcopenia (AWGS). Frailty ditegakkan melalui kuesioner skrining berdasarkan Cardiovascular Health Study. Penelitian dipilih dengan cara simple random sampling dan data register penduduk.

Hasil: Penelitian melibatkan 235 orang lanjut usia dengan jumlah 117 orang di desa Pedawe, 71 orang di desa Mangupura, 34 orang di desa Serai dan 13 orang di desa Songan dengan komposisi 35,5\% laki-laki dan 64,5\% perempuan. Pada penelitian ini sarkopenia pada perempuan adalah $51 \%$ dan laki-laki $49 \%$, sedangkan frailty dialami $58,9 \%$ perempuan dan $41,02 \%$ laki-laki. Rerata usia adalah 67,7 tahun. Prevalensi sarkopenia total adalah 59\% dengan persentase masingmasing mulai dari yang terendah adalah desa Mangupura (30\%), Songan (53,8\%), Pedawe (70,9\%), dan Serai (79,4\%). Prevalensi frailty keseluruhan di empat desa adalah $17 \%$ dengan persentase masingmasing mulai dari yang terendah adalah desa Mangupura (1,4\%), Serai (5,9\%), Songan (22,2\%) dan Pedawe $(29,1 \%)$.

Kesimpulan: Prevalensi sarkopenia dan frailty paling banyak ditemukan pada lansia perempuan. Prevalensi sarkopenia paling tinggi didapatkan di desa Serai dan prevalensi frailty didapatkan paling tinggi di desa Pedawe.
*Korespodensi:

I Gusti Agung Gde Wilaja Putra, Program Studi Pendidikan Dokter Spesialis Penyakit Dalam, Fakultas Kedokteran Universitas Udayana/ RSUP Sanglah, Denpasar, Bali, Indonesia

wilaja_putra@yahoo.co.id
Kata kunci: Lansia, sarkopenia, masa otot, frailty

Cite Pasal Ini: Putra, I.G.A.W., Aryana, I.G.P.S., Astika, I.N., Kuswardhani, R.A.T., Putrawan, I.B., Purnami, K.R. 2020. Prevalensi sarkopenia dan frailty di desa Pedawe, Mangupura, Serai dan Songan. Intisari Sains Medis 11(2): 546-550. D0I: 10.15562/ism.v11i2.667

\section{PENDAHULUAN}

Sarkopenia merupakan kondisi yang berhubungan dengan hilangnya masa otot yang progresif dan menyeluruh serta penurunan fungsi otot yang didefinisikan sebagai penurunan kekuatan otot 
dan/ atau tampilan fisik. Sarkopenia telah muncul sebagai suatu masalah yang paling sering pada populasi lanjut usia dan mewakili satu dari beberapa perhatian kesehatan masyarakat yang signifikan karena sarkopenia dapat memercepat terjadinya sindrom frailty. Sindrom frailty mengakibatkan isu kesehatan dan luaran klinis yang tidak diinginkan seperti keterbatasan fisik dan kecacatan, kualitas hidup yang buruk meningkatkan risiko jatuh, perumahsakitan, morbiditas, mortalitas, serta biaya perawatan kesehatan. ${ }^{1}$

Penurunan kesehatan dan peningkatan sindrom frailty sering diiringi oleh peningkatan usia. Walaupun usia secara kronologis dan biologis berhubungan, individu dengan peningkatan usia mungkin menunjukkan keragaman yang luas status kesehatan dan fungsional. Konsep frailty berusaha untuk menjelaskan heterogenisitas ini pada lanjut usia dan menjadikannya konsep yang penting untuk praktis klinis pembuatan kebijakan. Dari perspektif klinis, frailty penting karena terdiri dari risiko yang lebih besar untuk luaran yang tidak diinginkan seperti jatuh, mobilitas yang lebih rendah, penurunan kemandirian, perumahsakitan, disability dan kematian. Frailty tampak saat kapasitas cadangan telah menurun dibawah titik kritis, bahkan gangguan kecil dapat mengarah pada suatu seri komplikasi. Frailty adalah penting dari perspektif sosial karena ia mengidentifikasi kelompok orang dengan kebutuhan perhatian medis lebih. Frailty juga penting saat mempertimbangkan rencana biaya perawatan kesehatan. ${ }^{2}$

Pada umumnya, kehilangan masa otot yang progresif terjadi pada usia diatas 40 tahun yaitu $8 \%$ per dekade dan meningkat $15 \%$ per dekade setelah 70 tahun. Kekuatan otot menurun $10-15 \%$ per dekade dan lebih cepat setelah 70 tahun. Penelitian longitudinal masa otot, kekuatan genggaman dan kecepatan berjalan menurun setelah 4 tahun dalam komunitas lanjut usia di Cina. Hal ini menunjukkan bahwa lanjut usia memiliki masa otot yang lebih sedikit dan kekuatan genggaman yang lebih lemah dan kecepatan berjalan yang lebih lambat dibandingkan kulit hitam dan kulit putih pada usia yang sama. ${ }^{1}$ Pada umumnya diasumsikan bahwa prevalensi frailty meningkat seiring bertambahnya usia, lebih tinggi pada wanita dibandingkan pria dan lebih sering terjadi saat adanya penyakit kronis, namun tidak ada konsensus yang ada tentang angka prevalensi frailty. ${ }^{2}$ Penelitian ini bertujuan untuk mengetahui prevalensi sarkopenia dan frailty terutama didaerah pedesaan.

\section{BAHAN DAN METODE}

Penelitian ini menggunakan studi potong lintang pada populasi lansia di Bali meliputi empat desa yaitu desa Pedawe, Mangupura, Serai dan Songan. Penelitian dilakukan pada bulan September 2016 dan September 2017. Pengukuran masa otot dilakukan menggunakan BIA (Bioelectrical Impedance Analysis) merk Omron model HBF-510 dan dikategorikan berdasarkan rekomendasi AWGS (Asian Working Group for Sarcopenia). Frailty ditegakkan menggunakan kuesioner skrining berdasarkan Cardiovascular Health Study. Penelitian dilakukan dengan simple random sampling dan data register penduduk. Analisis statistik dilakukan menggunakan SPSS 24.0. Seluruh data dianalisis secara deskriptif.

\section{HASIL}

Penelitian melibatkan 235 orang lanjut usia dengan jumlah 117 orang di desa Pedawe, 71 orang di desa Mangupura, 34 orang di desa Serai dan 13 orang di desa Songan, dengan komposisi 35,5\% laki-laki dan $64,5 \%$ perempuan (Gambar 1). Pada penelitian ini sarkopenia pada perempuan adalah $51 \%$ dan lakilaki $49 \%$, sedangkan frailty dialami $58,9 \%$ perempuan dan 41,02\% laki-laki (Gambar 2). Rerata usia yang terlibat dalam penelitian yang disajikan dalam median (minimal-maksimal) adalah 67,7 tahun (60-100 tahun). Rerata umur untuk masing-masing desa dengan urutan umur yang semakin bertambah disajikan dalam nilai median (minimal-maksimal) adalah desa Mangupura 62 tahun (60-80 tahun), Songan 64 tahun (60-87), Pedawe 66 tahun (60-97 tahun), dan Serai 70 tahun (60-100 tahun) (Gambar 3). Prevalensi sarkopenia secara keseluruhan adalah 58,7\% dengan persentase masing-masing mulai dari yang terendah adalah desa Mangupura (30\%), Songan (53,8\%), Pedawe (70,9\%), dan Serai (79,4\%). Prevalensi frailty keseluruhan di empat desa adalah $17 \%$ dengan persentase masing-masing mulai dari yang terendah adalah desa Mangupura $(1,4 \%)$, Serai $(5,9 \%)$, Songan $(22,2 \%)$ dan Pedawe $(29,1 \%)$ (Gambar 4).

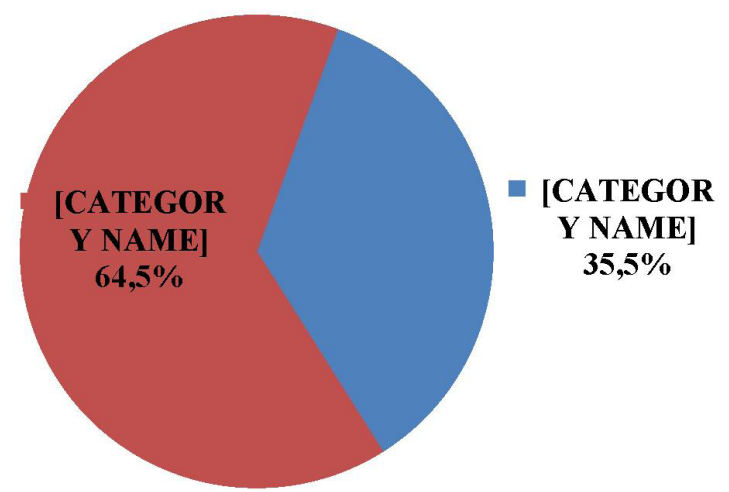

Gambar 1 Komposisi Lansia Berdasarkan Jenis Kelamin 


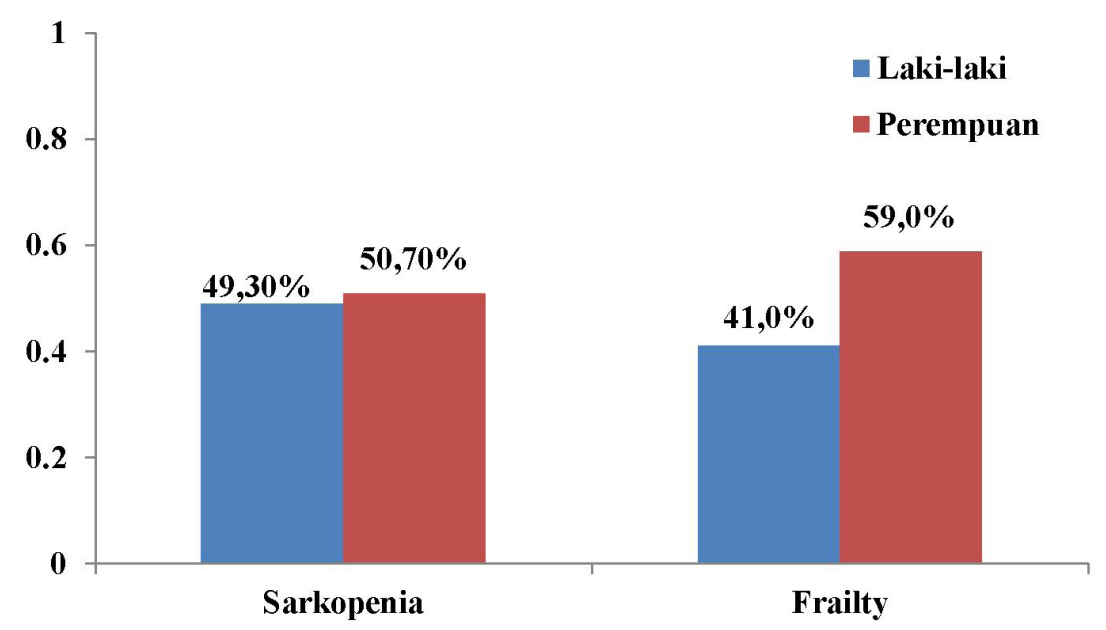

Gambar 2 Prevalensi Sarkopenia Dan Frailty Berdasarkan Jenis Kelamin

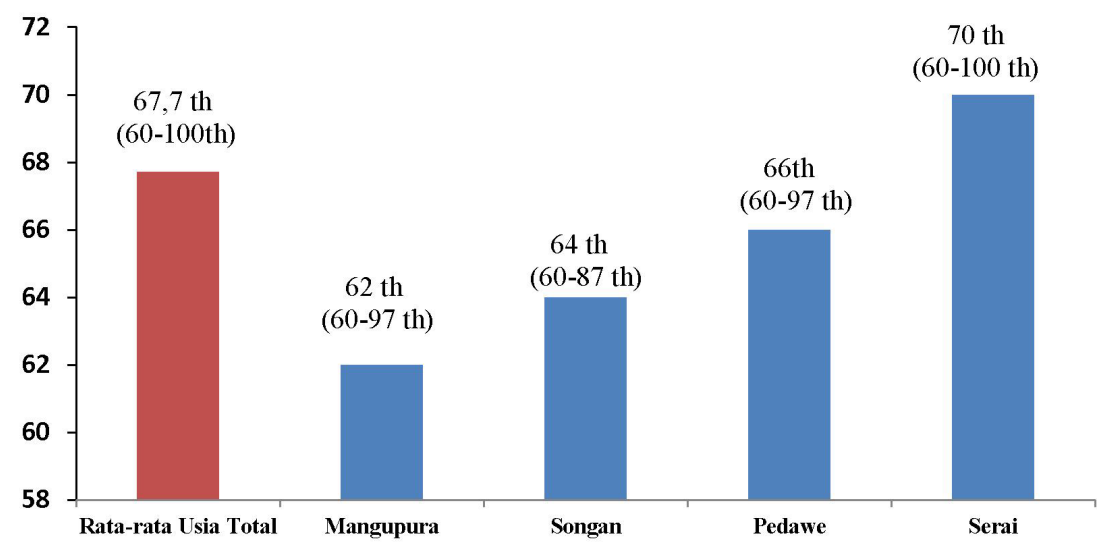

Gambar 3 Rerata Usia Lansia Total dan Pada Masing-Masing Desa Disajikan Dalam Median (Minimal-Maksimal)

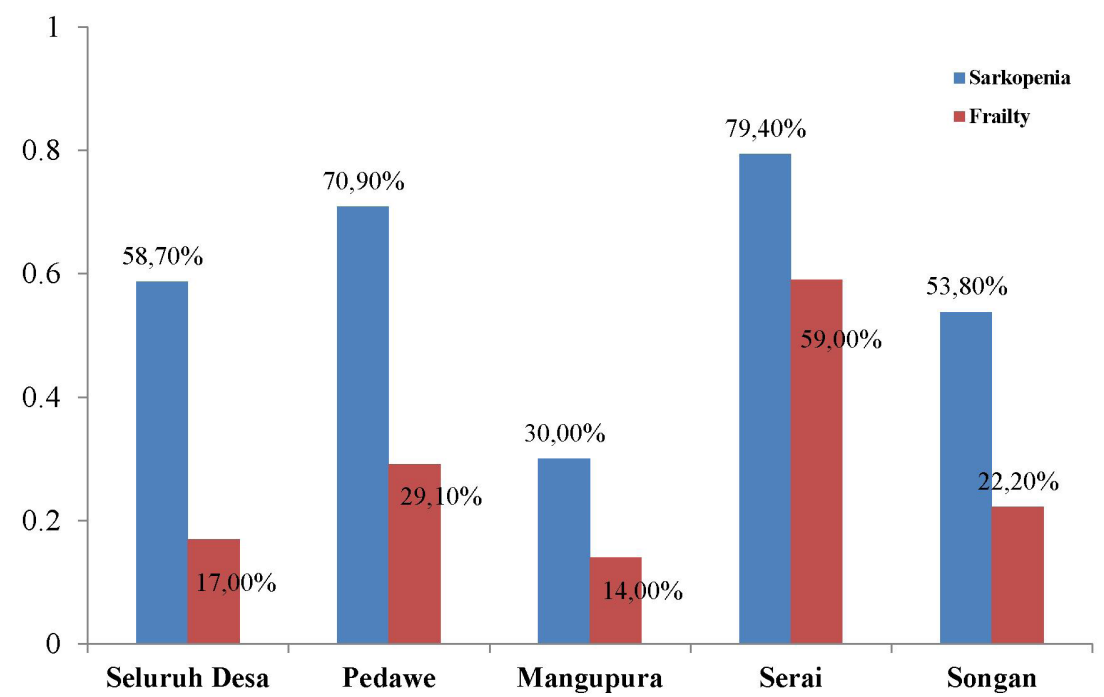

Gambar 4 Prevalensi Sarkopenia Dan Frailty Di Seluruh Dan MasingMasing Desa

Distribusi prevalensi sarkopenia pada masing masing desa berdasarkan jenis kelamin di desa Pedawe adalah 53,0\% untuk laki-laki dan $47 \%$ untuk perempuan, di desa Mangupura 23,8\% untuk laki-laki dan 76,2\% untuk perempuan, di desa Serai 59,3\% untuk laki-laki dan 40,7\% untuk perempuan dan di desa Songan 42,9\% untuk laki-laki dan $57,1 \%$ untuk perempuan. Distribusi frailty di desa Pedawe adalah 38,2\% untuk laki-laki dan $61,8 \%$ untuk perempuan, di desa Mangupura 0,0\% untuk laki-laki dan $100 \%$ untuk perempuan, di desa Serai $50 \%$ untuk laki-laki dan 50\% untuk perempuan, dan di desa Songan 100\% pada laki-laki dan 0\% untuk perempuan. Distribusi prevalensi dan frailty tersebut dapat dilihat pada tabel 1 .

Berdasarkan kelompok usia, prevalensi sarkopenia di desa Pedawe ditemukan 66,2\% pada kelompok usia 60-70 tahun dan 79,1\% pada kelompok usia > 70 tahun. Prevalensi sarkopenia di desa Mangupura didapatkan 29,5\% untuk kelompok usia 60-70 tahun dan $37,5 \%$ pada kelompok usia $>70$ tahun, di desa Serai 78,9\% untuk kelompok usia 60-70 tahun dan $80 \%$ pada kelompok usia $>70$ tahun, di desa Songan 54,5\% pada kelompok usia 60-70 dan 50\% pada kelompok $>70$ usia tahun. Distribusi frailty di desa Pedawe $18,9 \%$ pada kelompk usia 60-70 tahun dan $46,5 \%$ pada kelompok usia $>70$ tahun, di desa Mangupura 1,7\% pada kelompok usia 60-70 tahun dan 0,0\% pada kelompk usia $>70$ tahun, di desa Serai 0,0\% pada kelompok usia 60-70 tahun dan 13,3\% pada kelompok usia $>70$ tahun dan di desa Songan 12,5\% pada kelompok usia 60-70 tahun dan $100 \%$ pada kelompok usia $>70$ tahun. Distribusi tersebut ditampilkan pada tabel 2 .

\section{DISKUSI}

Prevalensi sarkopenia telah dilaporkan meningkat dengan cepat seiring bertambahnya usia. Prevalensi sarkopenia adalah sekitar 20\% diantara usia $>65$ tahun dan mungkin mencapai 50-60\% pada usia 80an. ${ }^{3}$ Prevalensi sarkopenia di Asia berbeda diantara negara, usia pada populasi penelitian, jenis kelamin, karakter populasi dan metode pengukuran. Terdapat prevalensi sarkopenia yang tidak konsisten diantara populasi Asia. ${ }^{1}$ Penelitian oleh Han dkk menunjukkan prevalensi sarkopenia adalah 6,4\% pada laki-laki dan $11 \%$ pada wanita. ${ }^{4}$ Penelitian lain oleh Ishii dkk juga menunjukkan prevalensi lebih tinggi pada perempuan $(22,1 \%)$ dibandingkan lakilaki $(14,2 \%) .{ }^{5}$ Penelitian yang dilakukan di daerah pedesaan di Bali menunjukkan prevalensi sarkopenia adalah 58,7\%, meningkat seiring bertambahnya usia dan lebih sering pada populasi perempuan. Prevalensi sarkopenia pada laki-laki adalah 49,3\% dan perempuan $50,7 \%$ sedangkan berdasarkan kelompok usia, 53,3\% pada kelompok 60-70 tahun dan $73,5 \%$ usia pada kelompok $>70$ tahun. 
Table 1 Distribusi Prevalensi Sarkopenia Dan Frailty Berdasarkan Jenis Kelamin

\begin{tabular}{|c|c|c|c|c|c|c|c|c|c|c|}
\hline \multirow[b]{2}{*}{ Jenis Kelamin } & \multicolumn{2}{|c|}{ Pedawe } & \multicolumn{2}{|c|}{ Mangupura } & \multicolumn{2}{|c|}{ Serai } & \multicolumn{2}{|c|}{ Songan } & \multicolumn{2}{|c|}{ Total } \\
\hline & $\mathbf{S}$ & $\mathbf{F}$ & $\mathbf{S}$ & $\mathbf{F}$ & $\mathbf{S}$ & $\mathbf{F}$ & $\mathbf{S}$ & $\mathbf{F}$ & $\mathbf{S}$ & $\mathbf{F}$ \\
\hline Laki-laki & $53,0 \%$ & $38,2 \%$ & $23,8 \%$ & $0,0 \%$ & $59,3 \%$ & $50,0 \%$ & $42,9 \%$ & $100,0 \%$ & $49,3 \%$ & $41,0 \%$ \\
\hline Perempuan & $47,0 \%$ & $61,8 \%$ & $76,2 \%$ & $100,0 \%$ & $40,7 \%$ & $50,0 \%$ & $57,1 \%$ & $0,0 \%$ & $50,7 \%$ & $59,0 \%$ \\
\hline
\end{tabular}

Keterangan: $\mathrm{S}=$ Sarkopenia; $\mathrm{F}=$ Frailty

Table 2 Distribusi Prevalensi Sarkopenia Dan Frailty Berdasarkan Kelompok Usia

\begin{tabular}{|c|c|c|c|c|c|c|c|c|c|c|}
\hline \multirow[b]{2}{*}{ Usia } & \multicolumn{2}{|c|}{ Pedawe } & \multicolumn{2}{|c|}{ Mangupura } & \multicolumn{2}{|c|}{ Serai } & \multicolumn{2}{|c|}{ Songan } & \multicolumn{2}{|c|}{ Total } \\
\hline & $\mathbf{S}$ & $\mathbf{F}$ & $\mathbf{S}$ & $\mathbf{F}$ & $\mathbf{S}$ & $\mathbf{F}$ & $\mathbf{S}$ & $\mathbf{F}$ & $\mathbf{S}$ & $\mathbf{F}$ \\
\hline $60-70$ th & $66,2 \%$ & $18,9 \%$ & $29,5 \%$ & $1,7 \%$ & $78,9 \%$ & $0,0 \%$ & $54,5 \%$ & $12,5 \%$ & $53,3 \%$ & $9,9 \%$ \\
\hline$>70$ th & $79,1 \%$ & $46,5 \%$ & $37,5 \%$ & $0,0 \%$ & $80,0 \%$ & $13,3 \%$ & $50,0 \%$ & $100,0 \%$ & $73,5 \%$ & $34,3 \%$ \\
\hline
\end{tabular}

Keterangan: $\mathrm{S}=$ Sarkopenia; $\mathrm{F}=$ Frailty

Berdasarkan definisi AWGS, pengukuran variabel termasuk masa otot, kekuatan otot (hand grip), dan performa fisik (kecepatan berjalan). Tantangannya adalah menentukan bagaimana cara pengukuran akurat terbaik khususnya appendicular skeletal muscle mass (ASM). Beberapa teknik telah digunakan untuk menilai ASM termasuk dual energy $x$-ray absorptiometry (DXA), computed tomography (CT), magnetic resonance imaging (MRI), dan bioelectrical impedance analysis (BIA). Bukti yang utuh dari penelitian pada cadaver menunjukkan bahwa DXA, MRI, dan CT memberikan pengukuran yang tepat dan terpercaya sebagai kriteria dalam mengukur ASM in vivo. Namun, faktor-faktor tertentu seperti biaya, aksesibilitas, dan masalah pajanan radiasi membatasi penggunaan pencitraan seluruh badan. Sebaliknya, BIA yang berdasarkan pengukuran konduktivitas jaringan dalam penelitian komposisi tubuh manusia adalah relatif sederhana, cepat (hanya perlu beberapa menit) dan tidak invasif. ${ }^{3}$ Alat ukur yang digunakan untuk mengukur skeletal muscle mass pada penelitian ini adalah merk Omron Full Body Sensor Body Composition Monitor and Scale Model $H B F-510$. Interpretasi hasil persentase masa otot pada perempuan dengan usia 60-80 tahun adalah normal bila berada pada rentang 23,9-29,9\% dan rendah apabila $<23,9 \%$. Untuk laki-laki dengan usia yang sama, persentase masa otot dikatakan normal bila berada pada rentang 32,9-38,9\% dan rendah bila $<32,9 \% .^{6}$

Sarkopenia mungkin mengarah pada frailty, namun tidak semua pasien sarkopenia adalah frail. Sarkopenia dua kali lebih sering dibandingkan frailty. ${ }^{7}$ Frailty biasa didapatkan pada lanjut usia namun perbedaan operasionalisasi status frailty menghasilkan perbedaan prevalensi dalam rentang yang luas diantara penelitian. ${ }^{2}$ Prevalensi frailty memiliki rentang antara 5\%-58\%. ${ }^{8}$ Penelitian lain oleh Merchant dkk menemukan prevalensi frailty 5,7\% - 11,3\%. Frailty berkorelasi secara signifikan dengan bertambahnya usia, jenis kelamin perempuan, multimorbiditas, polifarmasi, gangguan kognitif dan fungsional. ${ }^{9}$ Pada penelitian yang dilakukan di empat daerah pedesaan di Bali didapatkan prevalensi frailty 17\%. Prevalensi berada paling tinggi pada kelompok usia $>70$ th $(34,3 \%)$ dan 59\% dialami oleh lanjut usia perempuan.

Perempuan memiliki prevalensi frailty yang lebih tinggi dibandingkan laki-laki. Temuan ini tidak mengejutkan karena perempuan memiliki jumlah rerata masa otot dan kekuatan otot yang lebih rendah. Hubungan antara frailty dan sarkopenia telah terkonfirmasi pada penelitian terdahulu. Pada penelitian yang lain menunjukkan bahwa laki-laki memiliki kemungkinan untuk meninggal mendadak yang lebih besar dibandingkan perempuan sehingga pada perempuan terjadi penurunan progresif yang lebih lebih teratur sehingga menempatkan perempuan pada karakteristik frailty yang lebih tinggi. Kemungkinan penjelasan yang lain adalah harapan hidup lansia perempuan lebih panjang. Sebagai hasilnya, perempuan pada kelompok usia yang sama adalah lebih tua dibandingkan laki-laki. Karena frailty meningkat seiring usia, hal ini menyumbang terhadap perbedaan prevalensi antara jenis kelamin. ${ }^{2}$

Prevalensi sarkopenia dan frailty paling tinggi didapatkan di desa Serai. Hal ini mungkin karena rerata usia di desa Serai adalah paling tinggi diantara semua wilayah pedesaan pada penelitian ini sehingga prevalensi sarkopenia dan frailty meningkat seiring bertambahnya usia. Penelitian ini masih banyak kekurangan terutama meliputi jumlah sampel lansia yang yang terlibat mungkin tidak mewakili populasi lansia pada masing-masing desa dan jumlah keseluruhan lansia pada suatu desa yang belum diketahui secara pasti. Untuk itu 
masih diperlukan lagi penelitian-penelitian serupa dengan jumlah sampel yang lebis besar dengan jumlah lansia pada masing-masing desa yang lebih akurat sehingga bias pada penelitian bisa sekecil mungkin.

Penelitian ini masih banyak kelemahan. Jumlah sampel penelitian masih belum mewakili populasi penelitian secara keseluruhan. Kondisikondisi klinis pasien sebelum dilakukan pemeriksaan BIA, kecepatan berjalan dan kekuatan genggaman tangan tidak dievaluasi sehingga dapat memberikan hasil penelitian yang berbeda. Kemampauan memahami bahasa Indonesia pada sebagian besar pasien sampel lanjut usia sangat kurang sehingga akan memberikan bias pada pengisian kuesioner.

\section{SIMPULAN}

Prevalensi sarkopenia dan frailty secara keseluruhan di empat wilayah pedesaan di Bali yang meliputi desa Pedawe, Mangupura, Serai dan Songan adalah $58,7 \%$ dan $17 \%$. Berdasarkan jenis kelamin prevalensi sarkopenia dan frailty ditemukan paling banyak pada perempuan yaitu 51\% dan 58,9\%. Berdasarkan kelompok usia prevalensi sarkopenia dan frailty ditemukan paling banyak pada kelompok usia $>70$ tahun yaitu 73,5\% dan 34,3\%. Prevalensi sarkopenia dan frailty paling tinggi didapatkan di desa Serai yaitu sebanyak 79,4\% dan 59\%.

\section{ETIKA PENELITIAN}

Penelitian ini telah mendapat persetujuan etik dari komite Etik Fakultas Kedokteran Universitas Udayana, Bali, Indonesia sebelum penelitian berjalan.

\section{KONFLIK KEPENTINGAN}

Penulis menyatakan bahwa tidak terdapat konflik kepentingan dalam penulisan artikel ini.

\section{PENDANAAN}

Penulis bertanggung jawab penuh terhadap pendanaan penelitian ini tanpa melibatkan sponsor, grant, ataupun sumber pendanaan lainnya.

\section{KONTRIBUSI PENULIS}

Seluruh penulis berkontribusi bersama-sama dalam penyusunan artikel ini dari tahap usulan proposal, pengambilan data, analisis data, hingga interpretasi data penelitian.

\section{DAFTAR PUSTAKA}

1. Collard RM, Boter HB, Schoevers RA, dkk. Prevalence of frailty in community dwelling older person: a systematic review. J Am Geriatr Soc. 2012;60(8):1487-1492.

2. Han P, Kang L, Guo Q, dkk. Prevalence and factors associated with sarcopeniain suburb-dwelling older chinese using the asianworking group for sarcopenia definition. $J$ Gerontolog A Biol Sci Med Sci. 2015;0(0):1-7.

3. Ishii S, Tanaka T, Shibasaki K, dkk. Development of a simple screening test for sarcopenia in older adults. Geriatr Gerontol Int. 2014; 14 (Suppl. 1): 93-101.

4. Limpawattana P, Kotruchin P, dan Pongchaiyakul C. Sarcopenia in asia. Osteoporosis and sarcopenia. 2015;1: 92-97.

5. Merchant RA, Chen MZ, Tan LW, Lim MY, Ho HK. Singapore healthy older people everyday (HOPE) study: prevalence of frailty and associated factors in older adults. JAMDA. 2017:1.e1-1.e6.

6. Omron Health Care Inc. Instruction Manual Omron Full Body Sensor Body Composition Monitor and Scale Model HBF-510. Illinois: Omron Healthcare Inc; 2008.

7. Sternberg SA, Wershof Schwartz A. The identification of frailty: A systematic literature review. J Am Geriatr Soc. 2011;59:2129-2138.

8. von Haehling S, Morley JE, dan Anker SD. An overview of sarcopenia: facts and numbers on prevalence and clinical impact. J Cachexia Sarcopenia Muscle. 2010;1:129-133.

9. Wang H, Hai S, Zhou J, Liu P, Dong BR. Estimation of prevalence of sarcopenia by using a new bioelectrical impedance analysis in chinese community-dwelling elderly people. BMC Geriatrics. 2016;16(216): 1-9.

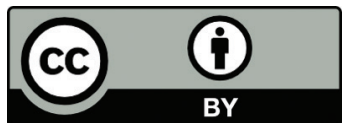

This work is licensed under a Creative Commons Attribution 